\title{
El Caribe llega al sertón
}

\author{
Isabel Ibarra Cabrera
}

\section{Revista Brasileira do Caribe}

Publicación del Centro de Estudios del Caribe en Brasil, Universidad Federal de Goiás, Goiânia.

o sertão vai virar mar e o mar vai virar sertão

¿P or qué la Revista Brasileira do Caribe? Para responder es necesario recorrer brevemente la trayectoria de las relaciones entre la revista, el contexto espacio-temporal en el que nació y conocer a su editora directora, la doctora Olga Cabrera. Desde luego que no es una tarea fácil, $y$ apenas me propongo ofrecer una síntesis para instigar a su lectura. En 1999 acompañé la creación del Centro de Estudios del Caribe en la Universi- dad Federal de Goiás (UFG), donde la profesora Cabrera comenzó a trabajar a principios de la década de 1990. Posteriormente, en 2000, participé en el lanzamiento de la revista. De una forma largamente planeada, el Caribe llegaba al sertón.

Conocida por su obra dedicada al estudio del movimiento obrero cubano, cuando Olga Cabrera llega a Brasil decide investigar la realidad brasileña y se adentra en el sertón goiano, donde realiza varios proyectos de investigación sobre las pequeñas propiedades rurales. Participaba

\section{The Caribbean Arrives to the Sertão}

Isabel Ibarra Cabrera: Facultad de Educación, Universidad Federal de Goiás, Goiânia, Brasil

isabelibarra555@hotmail.com

Desacatos, núm. 33, mayo-agosto 2010, pp. 187-188

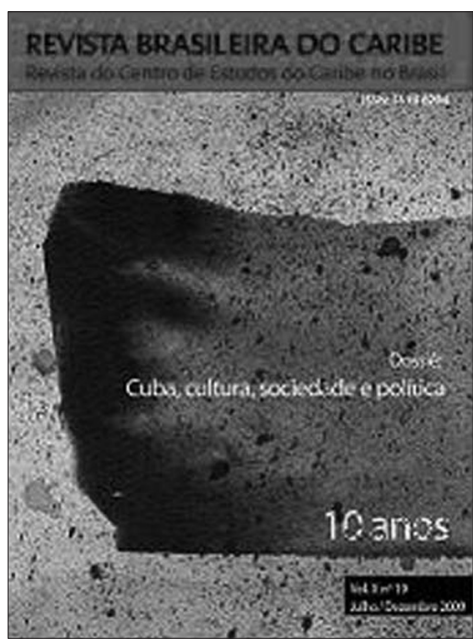

activamente de la formación de estudiantes en el Posgrado de Historia de las Sociedades Agrarias de la UFG, y, en el año 1998, después de realizar un posdoctorado en España, decide retomar el estudio de la realidad caribeña, especialmente la cubana. Con esa disposición, o vocación para inventarse pasiones, emprendió un nuevo proyecto: fundar el Centro de Estudios del Caribe (Cecab), en 1999. Un año después, realizó el Primer Congreso Internacional 
del Caribe y, con parcos recursos, editó el primer número de la Revista Brasileira do Caribe. No fueron pocos los obstáculos que tuvo que enfrentar dentro y fuera de la Universidad Federal de Goiás. De hecho, propuso y consiguió realizar una transformación del Posgrado, que se dedicaba a estudios regionales, para hacerlo más plural, en otras palabras, universalizarlo.

Así, en el año 2000 salió el primer número de la Revista Brasileira do Caribe con sólo siete artículos. A medida que pasaron los años, la revista fue ganando en calidad, proyecto gráfico y volumen (ahora incluye no menos de doce artículos en las tres lenguas principales del Caribe y en portugués). Actualmente, la revista está indexada por $L i$ -

\section{Latindex y la Universidad Nacional} Autónoma de México, y es avalada por el sistema de periódicos Capes/ Brasil en varias áreas del conocimiento. La publicación se ha caracterizado por tener coordinadores invitados para los volúmenes, tanto nacionales como internacionales, estimulando con ello que intelectuales brasileños que antes trabajaban de manera aislada y sin considerar las relaciones entre el contexto caribeño y Brasil se comprometan con el proyecto de la revista. También los simposios internacionales organizados por el Cecab han movilizado a intelectuales de todos los continentes para acudir a Goiás. Entre los principales logros de la revista está la pluralidad, tanto en los géneros que aborda - literatura, cine, historia, educación, antropología-, como en los temas y perspectivas teóricas que explora.

La Revista Brasileira do Caribe, de circulación semestral, posee un consejo editorial y científico internacional y ha publicado artículos de especialistas brasileños, mexicanos, cubanos, jamaicanos, martiniqueños, haitianos, alemanes, holandeses, franceses, sudafricanos, senegaleses, congoleses, ingleses, españoles, puertorriqueños y estadounidenses. La intensa gama de ideas expuestas se multiplica por medio del sitio $<$ www.revistabrasileiradocaribe.org $>$, que ofrece digitalizados números anteriores y entra en contacto con otras revistas e instituciones, además de mantener su apoyo a las actividades del Cecab. Esta dinámica coloca a la Revista Brasileira do Caribe y al Cecab en el nivel de los grandes centros dedicados al estudio del Caribe y de las culturas afroamericanas.

Por último, las relaciones entre el Caribe y el sertón no son accidentales. Pueden y deben estrecharse porque, como dice Riobaldo, personaje del novelista Guimarães Rosa, "mestre no es quien siempre enseña sino el que de repente aprende". Por eso pienso que no sólo el sertón se ha tornado Caribe, sino que también el Caribe puede tornarse sertón. El diálogo, "la relación poética" (Edouard Glissant) entre Brasil y el Caribe es intensa. Si bien la literatura, la música, la cultura y la historia caribeñas han llegado a ese país, también el Caribe tiene que aprender con la literatura, la cultura, el cine, la música brasileña, con Guimarães Rosa, con Euclides da Cunha, con el cineasta Glauber Rocha, entre muchos otros. Creo que después de dieciocho números, la Revista Brasileira do Caribe, sus gestores y colaboradores están, como dijo Alejo Carpentier, "en busca de los pasos perdidos". Invito al lector a incursionar en ese viaje lleno de imprevistos. 